\title{
Optical Properties of Vanadium Ions in Zinc Sulphide
}

\author{
H.-J. Schulz and G. Roussos \\ Fritz-Haber-Institut der Max-Planck-Gesellschaft, Berlin (West), Germany
}

S. W. Biernacki

Institute of Physics, Polish Academy of Sciences, Warsaw, Poland

Z. Naturforsch. 45a, 669-676 (1990); received January 11, 1990

\begin{abstract}
The luminescence of synthetic $\mathrm{ZnS}: \mathrm{V}$ crystals is studied at low temperatures $(T \approx 4 \mathrm{~K})$. The emission spectra comprise (i) a structured band centred around $\bar{v}=5600 \mathrm{~cm}^{-1}$, assigned to ${ }^{3} \mathrm{~T}_{2}(\mathrm{~F}) \rightarrow{ }^{3} \mathrm{~A}_{2}(\mathrm{~F})$ transitions of substitutional $\mathrm{V}^{3+}\left(3 \mathrm{~d}^{2}\right)$ ions in a tetrahedral field, and (ii) a band around $4800 \mathrm{~cm}^{-1}$, assigned to ${ }^{4} \mathrm{~T}_{2}(\mathrm{~F}) \rightarrow{ }^{4} \mathrm{~T}_{1}(\mathrm{~F})$ transitions of $\mathrm{V}^{2+}\left(3 \mathrm{~d}^{3}\right)$ ions. In the range of the narrow no-phonon lines detected with both these emission bands, a temperature rise from 2 to $5 \mathrm{~K}$ entails a thermalisation in the population of the spin-orbit multiplets forming the initial states of the corresponding transitions. A third emission band near $3800 \mathrm{~cm}^{-1}$ grows after annealing the crystals in $\mathrm{Zn}$ vapour. It is tentatively attributed to ${ }^{5} \mathrm{E}(\mathrm{D}) \rightarrow{ }^{5} \mathrm{~T}_{2}$ (D) transitions of $\mathrm{V}^{+}\left(3 \mathrm{~d}^{4}\right)$. A model of one-electron states represents donor-type as well as acceptor-type changes of the vanadium oxidation states, commencing from $\mathrm{V}^{2+}$, the state with neutral effective charge. The model is substantially founded on the measured excitation spectra of the $\mathrm{V}^{3+}$ and $\mathrm{V}^{2+}$ emission bands, supplemented by transmission spectra. Besides the corresponding broad charge transfer bands, the spectra display a number of structures which are associated with excited states of the ions. These energy levels are approximated in a computation following the strong-field Tanabe-Sugano scheme but in addition allowing for different radial extensions of $\mathrm{e}$ - and $\mathrm{t}_{2}$-type wave functions. The method used also includes the possibility of fitting the free-ion levels. Various sets of numerical values are eventually obtained for the crystal-field splitting and the Racah parameters. Some of the levels involved are found to be subject to Jahn-Teller interaction.
\end{abstract}

\begin{abstract}
Key words: $71.55 \mathrm{~F}$ Impurity and defect levels (tetrahedrally bonded nonmetals); - 71.70 Level splittings and interactions; - 78.30 G Infrared spectra (nonmetallic inorganic crystals); - 78.50 G Impurity absorption (semiconductors); - 78.55 D Photoluminescence (tetrahedrally bonded nonmetals).
\end{abstract}

\section{Introduction}

The sulphides and selenides of zinc and cadmium were shown to be luminescent as powdered materials by Avinor and Meijer [1], and not only their broadband emission spectra but also excitation spectra of photoluminescence were studied as early as 1960 [2]. These data formed the basis for an interpretation by means of conventional crystal field theory [3], relating the emission to a ${ }^{3} \mathrm{~T}_{2}(\mathrm{~F}) \rightarrow{ }^{3} \mathrm{~A}_{2}(\mathrm{~F})$ transition of a $\mathrm{V}^{3+}\left(\mathrm{d}^{2}\right)$ ion in tetrahedral coordination. This very oxidation state was then detected in a photo-ESR experiment with $\mathrm{ZnS}: \mathrm{V}$ [4]. A poorly resolved emission band of $\mathrm{ZnS}: \mathrm{V}$ peaking near $5400 \mathrm{~cm}^{-1}$ was later attributed to $\mathrm{V}^{2+}\left(\mathrm{d}^{3}\right)$ [5], following an experimental verification of an appearance of $\mathrm{V}^{2+}$ ions in ZnS by ESR [6]. Apart from a more detailed publica-

Correspondence and reprint requests to Prof. Dr. H.-J. Schulz, Fritz-Haber-Institut der MPG, Faradayweg 4-6, D-1000 Berlin 33. tion on CdS: V [7], no extensive investigation of the optical properties of vanadium-doped II-VI semiconductors was carried out until recently. The present study contains experimental evidence for the simultaneous presence of different charge states of vanadium ions in $\mathrm{ZnS}$ (cf. [8]). The results become comprehensible in a model of energy levels of $\mathrm{V}^{3+}\left(\mathrm{d}^{2}\right)$ and $\mathrm{V}^{2+}\left(\mathrm{d}^{3}\right)$ ions (cf. [9]).

\section{Emission Spectra}

The photoluminescence of an as-grown $\mathrm{ZnS}: \mathrm{V}$ crystal is dominated, under broad-band excitation, by structured emission bands centred near 5600 and $4800 \mathrm{~cm}^{-1}$ (Figure 1). The overall appearance of the higher-energy band resembles very closely that of corresponding emissions of GaAs: $\mathrm{V}$ and InP: $\mathrm{V}$. Consequently, an interpretation as ${ }^{3} \mathrm{~T}_{2}(\mathrm{~F}) \rightarrow{ }^{3} \mathrm{~A}_{2}(\mathrm{~F})$ transition of $\mathrm{V}^{3+}\left(\mathrm{d}^{2}\right)$ is here prepared in analogy to the

0932-0784 / $90 / 0500-0669 \$ 01.30 / 0$. Please order a reprint rather than making your own copy. 


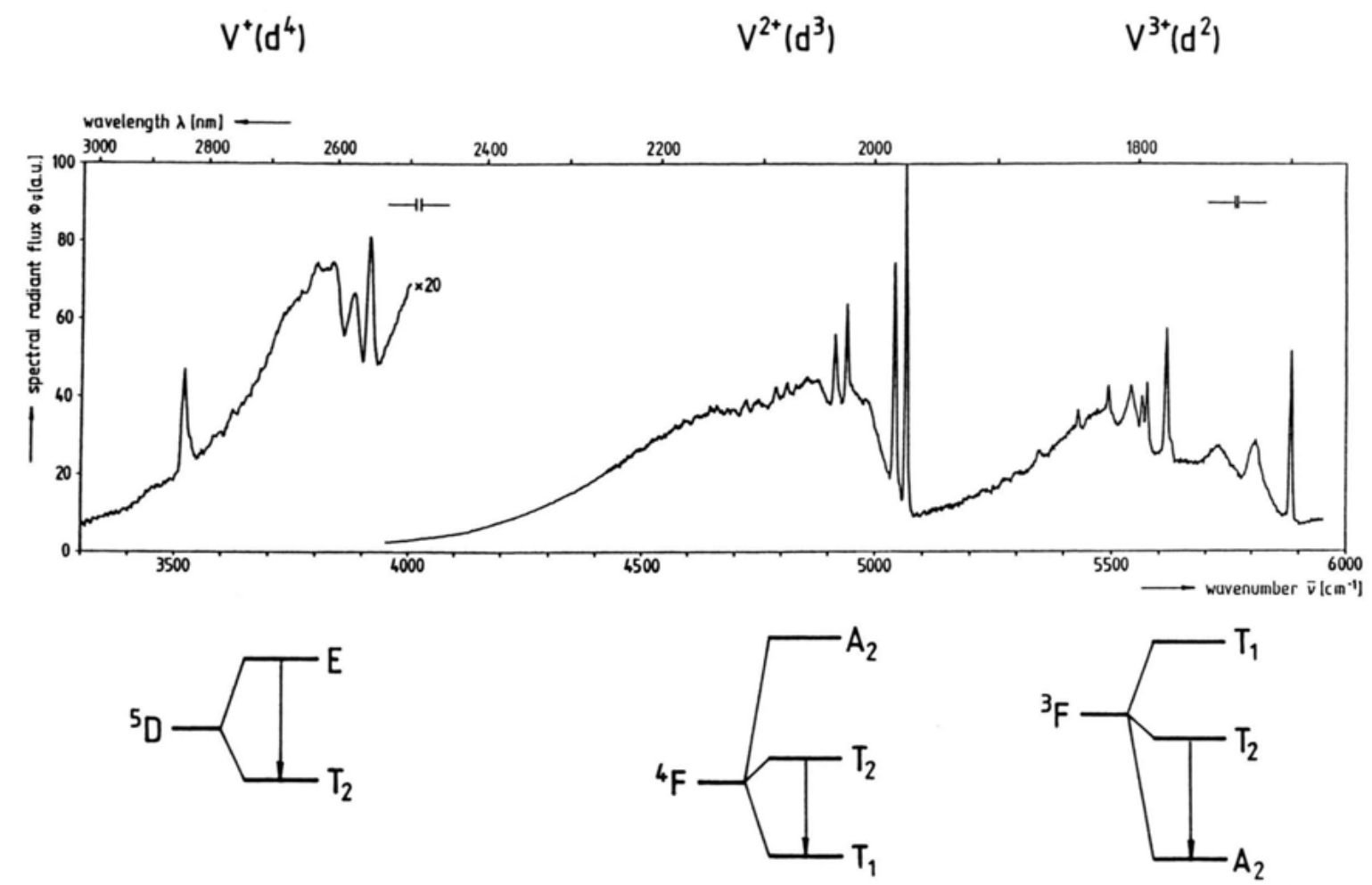

Fig. 1. Low-temperature ( $T \approx 4 \mathrm{~K}$ ) emission of a synthetic $\mathrm{ZnS}: \mathrm{V}$ crystal (100 ppm $\mathrm{V}$ added) and schematic level diagrams of the crystal-field transitions to which the respective luminescence bands are assigned. (No corrections applied to the spectra for $\mathrm{PbS}$ detector sensitivity and spectrometer properties. Excitation in the $16500-27000 \mathrm{~cm}^{-1}$ range.)

III-V host lattices where it is supported by ESR, Zeeman and uniaxial-stress experiments [10-16].

On increasing the temperature of the sample from 2 to $5 \mathrm{~K}$ by raising the irradiance as indicated in Fig. 2, the $5878 \mathrm{~cm}^{-1}$ main line develops a "hot satellite" at $5889 \mathrm{~cm}^{-1}$. This observation proves a thermalisation in the occupancy of the initial state involved in this emission transition, an effect known alike from GaAs and GaP. This conclusion is supported by the behaviour of the $5610 \mathrm{~cm}^{-1}$ line, a $\mathrm{TO}(\Gamma)$ phonon replica of the aforementioned main line. Here, a "hot line" is likewise produced by a temperature increase (Fig. 3) so that a $10 \mathrm{~cm}^{-1}$ splitting of the excited state is inferred. It has been attributed to combined influence of spin-orbit and Jahn-Teller couplings in the initial ${ }^{3} \mathrm{~T}_{2}(\mathrm{~F})$ state, resulting in a higher $\mathrm{T}_{1}+\mathrm{T}_{2}$ and a lower $\mathrm{A}_{2}+\mathrm{E}$ level $[12-15,17]$.

The most prominent structure in the emission band centred around $4800 \mathrm{~cm}^{-1}$ is a doublet at 5061 and $5033 \mathrm{~cm}^{-1}$ (Figure 1). It is replicated twice with a shift of $125 \mathrm{~cm}^{-1}$ towards lower energies, possibly related to a maximum $\operatorname{TA}(\Sigma)$ in the phonon dispersion dia- gram of cubic $\mathrm{ZnS}$, i.e. near the $\mathrm{K}$ point [18]. The doublet separation of $28 \mathrm{~cm}^{-1}$ apparently reflects a splitting in the final state of the emission. The total of experimental facts, including the excitation spectra, to be discussed hereafter, suggests an interpretation of this band as ${ }^{4} \mathrm{~T}_{2}(\mathrm{~F}) \rightarrow{ }^{4} \mathrm{~T}_{1}(\mathrm{~F})$ transition of $\mathrm{V}^{2+}\left(\mathrm{d}^{3}\right)$. Both $T_{2}$ and $T_{1}$ being liable to Jahn-Teller coupling, a simple spin-orbit mechanism is evidently insufficient for predicting the pattern of sublevels for these crystal field levels in the vibronic limit. Some considerations can be based on the thermalisation properties of the principal doublet, with the consequence that a $\Gamma_{7}$ component of ${ }^{4} \mathrm{~T}_{1}(\mathrm{~F})$ would here form the ground state [9].

On the low-energy tail of the luminescence spectrum, some additional structure is discernible around $3800 \mathrm{~cm}^{-1}$. The doublet farthest to the left in Fig. 1, i.e. at 3533 and $3520 \mathrm{~cm}^{-1}$, is not a true constituent of this structure, since it can be traced back to $\mathrm{Ni}^{+}$and $\mathrm{Co}^{2+}$ ions [18 a] which have inadvertently entered this particular crystal. The main line in this range, near $3900 \mathrm{~cm}^{-1}$, is, however, for the time being assigned to 

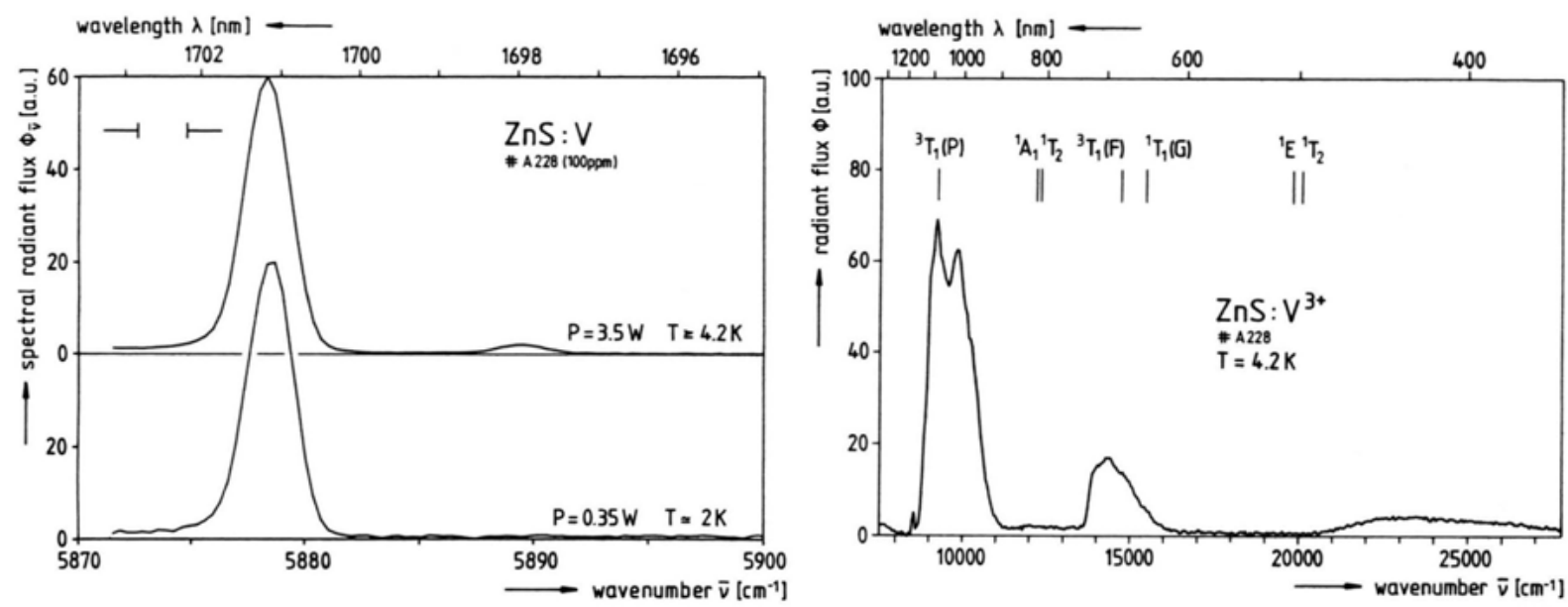

Fig. 2. $5878 \mathrm{~cm}^{-1}$ main line in the $\mathrm{V}^{3+}\left(\mathrm{d}^{2}\right)$ photoluminescence and the $5889 \mathrm{~cm}^{-1}$ "hot" line which appears at a slightly elevated temperature produced by an increase of the exciting
radiant power $P$ (YAG $: \mathrm{Nd}^{3+}$ laser, near $\bar{v}=9400 \mathrm{~cm}^{-1}$ ).

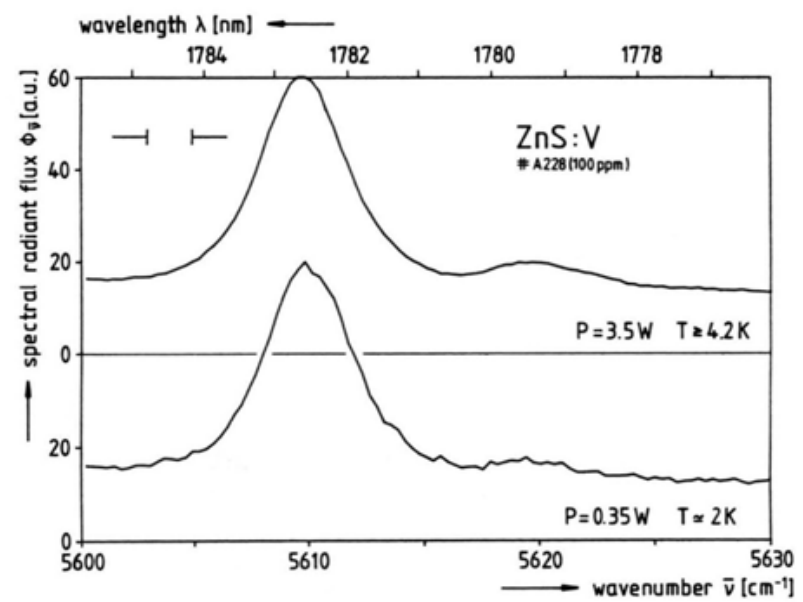

Fig. 3. The $\mathrm{TO}(\Gamma)$ satellite in the $\mathrm{V}^{3+}\left(\mathrm{d}^{2}\right)$ photoluminescence at $5610 \mathrm{~cm}^{-1}$ and the "hot" line at $5620 \mathrm{~cm}^{-1}$ which is enlarged on increasing the radiant power $\mathrm{P}$ of the exciting YAG: $\mathrm{Nd}^{3+}$ laser $\left(\bar{v} \approx 9400 \mathrm{~cm}^{-1}\right)$.

the ${ }^{5} \mathrm{E}(\mathrm{D}) \rightarrow{ }^{5} \mathrm{~T}_{2}(\mathrm{D})$ transition of $\mathrm{V}^{+}\left(\mathrm{d}^{4}\right)$. The general appearance of the annexed phonon-coupled range bears enough resemblance to the emission of the isoelectronic $\mathrm{Cr}^{2+}$ ion [19] to infer, likewise, e-mode Jahn-Teller coupling.

\section{Excitation Spectra}

The clear partition of the emission bands assigned to $\mathrm{V}^{3+}\left(\mathrm{d}^{2}\right)$ in the 5100 to $5900 \mathrm{~cm}^{-1}$ range and to $\mathrm{V}^{2+}\left(\mathrm{d}^{3}\right)$ in the 4000 to $5100 \mathrm{~cm}^{-1}$ range (cf. Fig. 1)

Fig. 4. Excitation spectrum of the ${ }^{3} \mathrm{~T}_{2}(\mathrm{~F}) \rightarrow{ }^{3} \mathrm{~A}_{2}(\mathrm{~F})$ photoluminescence of the $\mathrm{V}^{3+}\left(\mathrm{d}^{2}\right)$ ion in as-grown $\mathrm{ZnS}: \mathrm{V}$ at $T \approx 4.2 \mathrm{~K}$. Emission detected in the $5350-6050 \mathrm{~cm}^{-1}$ range (cf. Figure 1). Calculated eigenvalues included for comparison (see Section 6).

permits recording of excitation spectra for these ranges separately by means of selective filters, transmissive in the respective spectral regions. In the $\mathrm{V}^{3+}$ excitation spectrum (Fig. 4), the prevailing features are a structured band near $10000 \mathrm{~cm}^{-1}$, preceded by a line at $8500 \mathrm{~cm}^{-1}$, another band near $14000 \mathrm{~cm}^{-1}$ and a weak broad high-energy band characterised by a leading edge at approximately $20500 \mathrm{~cm}^{-1}$. The dominating double-peaked band near $10000 \mathrm{~cm}^{-1}$ is found with a surprisingly similar contour in the lowtemperature absorption $[20,21]$ and excitation spectrum of $\mathrm{GaAs}: \mathrm{V}^{3+}[22,23]$. Other $\mathrm{V}^{3+}$-related spectra bear strong resemblance to this shape as well, e.g. those of InP:V [16, 21] and of CdS:V [7]. This agreement strongly supports the present assignment of the $5600 \mathrm{~cm}^{-1}$ band to internal $\mathrm{V}^{3+}$ transitions.

A completely different excitation spectrum is obtained for the emission band centred near $4800 \mathrm{~cm}^{-1}$. It consists of six bands below $20000 \mathrm{~cm}^{-1}$, approx. $1000 \mathrm{~cm}^{-1}$ wide, and of at least two broad-band structures above $20000 \mathrm{~cm}^{-1}$ (Figure 5). This spectrum is here assigned to excitation of the $\mathrm{V}^{2+}$ ion, a supposition which will be substantiated by further theoretical evidence in Section 6. A corresponding spectrum is not known for the III-V semiconductors (although $\mathrm{V}^{2+}$ absorption structures have been recorded with $\mathrm{n}$-GaAs (cf. [21, 24]). The reason is evidently the peculiarity of $\mathrm{V}^{2+}$ in GaAs, that it would take a low-spin configuration $t_{2}^{0} \mathrm{e}^{3}$ instead of the $\mathrm{t}_{2}^{1} \mathrm{e}^{2}$ high-spin configuration expected for $\mathrm{ZnS}[25,26]$. 


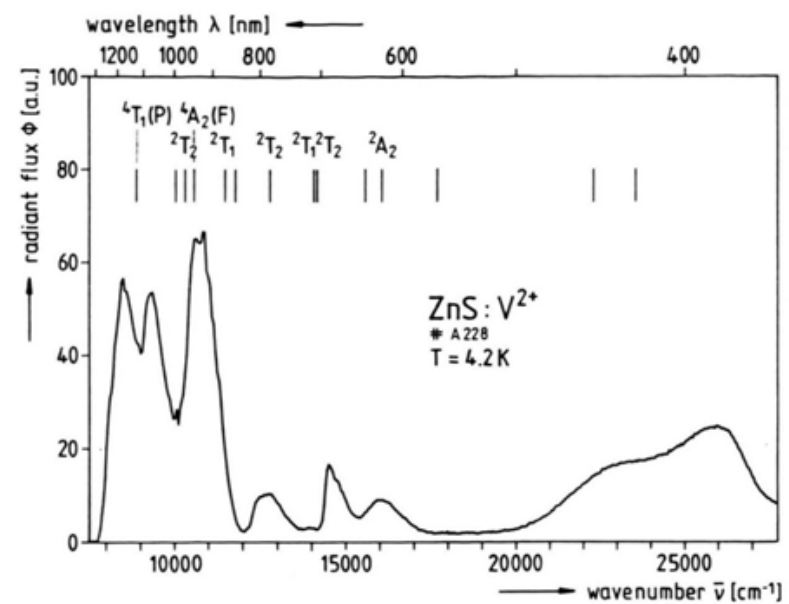

Fig. 5. Excitation spectrum of the ${ }^{4} \mathrm{~T}_{2}(\mathrm{~F}) \rightarrow{ }^{4} \mathrm{~T}_{1}(\mathrm{~F})$ photoluminescence of the $\mathrm{V}^{2+}\left(\mathrm{d}^{3}\right)$ ion in as-grown $\mathrm{ZnS}: \mathrm{V}$ at $T \approx 4 \mathrm{~K}$. Emission detected in the $4250-5000 \mathrm{~cm}^{-1}$ range (cf. Figure 1). Calculated eigenvalues included for comparison (see Section 6).

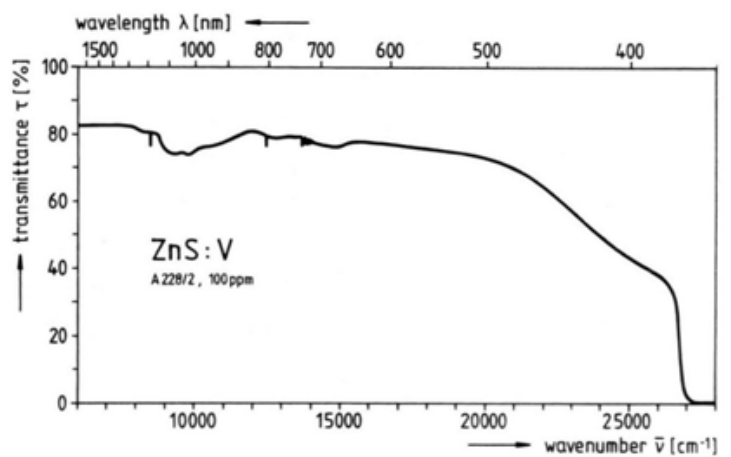

Fig. 6. Transmission spectrum of an as-grown $\mathrm{ZnS}$ : V crystal at $T \approx 10 \mathrm{~K}$, recorded by a double-beam spectrometer.

\section{Transmission Spectra}

The sensitivity of an absorption measurement for the detection of a particular transition is generally less than that of luminescence-related methods if these methods are at all applicable to the studied species. With the V-doped samples under study here, a number of narrow "lines" could be detected at $T \approx 10 \mathrm{~K}$ apart from broad unstructured absorption regions towards higher energies, which eventually merge into the tail of interband transitions. The line near $12400 \mathrm{~cm}^{-1}$ indicates the presence of $\mathrm{Ni}^{2+}\left(\mathrm{d}^{8}\right)$ ions by their internal ${ }^{3} \mathrm{~T}_{1}(\mathrm{P}) \leftarrow{ }^{3} \mathrm{~T}_{1}(\mathrm{~F})$ transition $[27-29]$. The lines at approximately 8500 and $13700 \mathrm{~cm}^{-1}$ lie near the low-energy edges of excitation bands in
Fig. 4, thus indicating the presence of $\mathrm{V}^{3+}$ in the asgrown $\mathrm{ZnS}: \mathrm{V}$ crystal. The broad structures in the 20000 to $25000 \mathrm{~cm}^{-1}$ region, finally, are of the wellknown charge-transfer type and correspond satisfactorily to excitation structures in Figs. 4 and 5. The onset of these transitions is already visible in an absorption spectrum of LeManh and Baranowski [5]. The medium-resolution spectrum of Fig. 6 thus conforms with the excitation spectra and the conclusions drawn therefrom.

\section{Energy Levels of Vanadium Ions in $\mathrm{ZnS}$}

To visualise donor- and acceptor-type transitions in semiconductor materials, numerous models have been devised which comprise the energy levels of impurities and the respective energy bands of the host lattice (e.g. [30-32]). Not the weak-field many-electron levels customarily used to describe the internal transitions seen in excitation spectra are the appropriate representation for the one-electron band-picture, but the correlated strong-field one-electron states (e.g. [33,34]). For the present purpose, only the ground and first excited states of the impurity ion are of concern, but even here, there is no one-to-one correspondence of lowfield and high-field levels. Therefore, only the prevalent labels are given in Fig. 7 for the configurations involved. An example of a more complicated situation will be discussed for $\mathrm{V}^{2+}$ in Section 6 .

The model of one-electron configurations (Fig. 7, which also shows the meaning of the symbols used) comprises the $t_{2}$ - and e-type levels of the vanadium oxidation states $\mathrm{V}^{3+}, \mathrm{V}^{2+}$, and $\mathrm{V}^{+}$as well as the first excited states of these, each marked by an asterisk. For substitutional $\mathrm{V}_{\mathrm{Zn}}$, the $\mathrm{V}^{2+}$ charge state is quasi-neutral, i.e. the initial state for donor-type $\mathrm{D}^{\times} \rightleftarrows \mathrm{D}^{*}+\mathrm{e}^{\prime}$ and acceptor-type processes $\mathrm{A}^{\times} \rightleftarrows \mathrm{A}^{\prime}+\mathrm{e}^{*}$. The lower (e) level of $\mathrm{V}^{2+}$ corresponds to the " $\mathrm{V}^{3+} / \mathrm{V}^{2+}$ donor level", the upper $\left(\mathrm{t}_{2}\right)$ level of $\mathrm{V}^{+}$to the " $\mathrm{V}^{2+} / \mathrm{V}^{+}$acceptor level" of vanadium in the $\mathrm{ZnS}$ host lattice. In addition to the conversion transitions involving either $\mathrm{t}_{2}$ - or e-levels of the impurity, also internal transitions are depicted which take place between $t_{2}$ - and e-levels of the respective ion, viz. the presumptive three radiative transitions of $\mathrm{V}^{3+}, \mathrm{V}^{2+}$, and $\mathrm{V}^{+}$(cf. [9]).

While the model implies approximately 15000 and $24000 \mathrm{~cm}^{-1}$ for the simple donor or acceptor transitions, the supposition that $20000 \mathrm{~cm}^{-1}$ are required to photoionize one of the e orbitals of the $\mathrm{V}^{2+}$ ground 


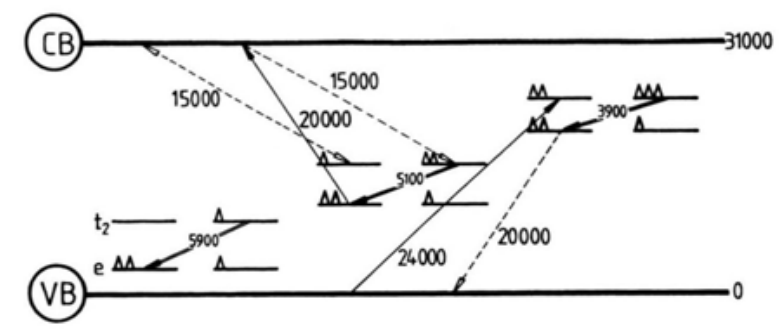

configuration strong-field qu.n. low-field label $\left(\mathrm{T}_{\mathrm{d}}\right)$ effective charge ion charge

$\begin{array}{ccccc}\mathrm{d}^{2} & \left(\mathrm{~d}^{2}\right)^{*} & \mathrm{~d}^{3} & \left(\mathrm{~d}^{3}\right)^{*} & \mathrm{~d}^{4} \\ \mathrm{e}^{2} & \mathrm{t}_{2} \mathrm{e} & \mathrm{t}_{2} \mathrm{e}^{2} & \mathrm{t}_{2}^{2} \mathrm{e}^{2} & \mathrm{t}_{2}^{2} \mathrm{e}^{2} \\ { }^{3} \mathrm{~A}_{2}(\mathrm{~F}) & { }^{3} \mathrm{~T}_{2}(\mathrm{~F}) & { }^{4} \mathrm{~T}_{1}(\mathrm{~F}) & { }^{4} \mathrm{~T}_{2}(\mathrm{~F}) & { }^{5} \mathrm{~T}_{2}(\mathrm{D}) \\ \mathrm{D}^{\mathrm{D}} & \mathrm{D}^{* *} & \mathrm{D}^{\times} \equiv \mathrm{A}^{\times} & \mathrm{A}^{\times *} & \mathrm{~A}^{\times} \\ \mathrm{V}^{3+} & \mathrm{V}^{3+*} & \mathrm{~V}^{2+} & \mathrm{V}^{2+*} & \mathrm{~V}^{+}\end{array}$

$\left(\mathrm{d}^{4}\right)^{*}$

$\mathrm{t}_{2}^{3} \mathrm{e}$

${ }^{5} \mathrm{E}(\mathrm{D})$

$\mathrm{A}^{\prime *}$
Fig. 7. Changes in the vanadium charge states depicted in a model of one-electron configurations. Abscissa represents $\mathrm{V}$ oxidation and excitation states, ordinate gives transition energies (dashed lines are used for transitions which are not experimentally confirmed. Positions of $\mathbf{V}^{3+}$ levels are supposed). state leads to an explanation of the first threshold observed in the excitation spectra (Figs. 4 and 5):

$$
\mathrm{V}^{2+}+20000 \mathrm{~cm}^{-1} \rightarrow \mathrm{V}^{3+*}+\mathrm{e}_{\mathrm{CB}}^{-} \text {. }
$$

Depending on whether the excited $\mathrm{V}^{3+}$ ion will emit at first, followed by capture of the conduction electron $\mathrm{e}_{\mathrm{CB}}^{-}$,

$$
\begin{aligned}
\mathrm{V}^{3+{ }^{*}}+\mathrm{e}_{\mathrm{CB}}^{-} & \rightarrow \mathrm{V}^{3+}+5900 \mathrm{~cm}^{-1}+\mathrm{e}_{\mathrm{CB}}^{-} \\
& \rightarrow \mathrm{V}^{2+}\left(+\underset{\text { not observed }}{\left.15000 \mathrm{~cm}^{-1}\right),}\right.
\end{aligned}
$$

or the recombination will precede the internal relaxation,

$$
\begin{aligned}
\mathrm{V}^{3+*}+\mathrm{e}_{\mathrm{CB}}^{-} & \rightarrow \mathrm{V}^{2+*}\left(+\underset{\text { not observed }}{15000 \mathrm{~cm}^{-1}}\right) \\
& \rightarrow \mathrm{V}^{2+}+5100 \mathrm{~cm}^{-1},
\end{aligned}
$$

either the $\mathrm{V}^{3+}$ or the $\mathrm{V}^{2+}$ emission will result.

The second threshold near $24000 \mathrm{~cm}^{-1}$ is only present in the $\mathrm{V}^{2+}$ excitation spectrum (Fig. 5). It can correspondingly be related to acceptor-like transitions:

$$
\mathrm{V}^{2+}+24000 \mathrm{~cm}^{-1} \rightarrow \mathrm{V}^{+}+\mathrm{e}_{\mathrm{VB}}^{+},
$$

where $\mathrm{e}_{\mathrm{VB}}^{+}$denotes a hole in the valence band. In analogy to reaction (3), hole capture would entail an excited $\mathrm{V}^{2+*}$ state which then would emit its characteristic luminescence:

$$
\begin{aligned}
\mathrm{V}^{+}+\mathrm{e}_{\mathrm{VB}}^{+} & \rightarrow \mathrm{V}^{2+*}\left(+\underset{\text { not observed }}{2000 \mathrm{~cm}^{-1}}\right) \\
& \rightarrow \mathrm{V}^{2+}+5100 \mathrm{~cm}^{-1} .
\end{aligned}
$$

Comparing the effects reflected in the measured excitation spectra, one would call the combination of processes (1) and (2) a fairly ineffective way of excitation whereas the sequence (1) and (3) and even more so (4) and (5) seem to be comparatively efficient mechanisms.

The properties of the emission near $3800 \mathrm{~cm}^{-1}$ certainly deserve more attention in the future. Annealing of the crystals in $\mathrm{Zn}$ vapour seems to favour this band. This observation agrees in any case with the supposition that an elevation of the Fermi level should increase the number of $\mathrm{V}^{+}\left(\mathrm{d}^{4}\right)$ centres. With $\mathrm{ZnO}$ : $\mathrm{V}$, for example, a $d^{2} \rightarrow d^{3}$ conversion has been confirmed under these conditions [35]. In the annealed $\mathrm{ZnS}$ samples, an absorption band near $4500 \mathrm{~cm}^{-1}$ is enhanced by "blue" light irradiation. It is thought to correspond to the absorption transition inverse to the $3800 \mathrm{~cm}^{-1}$ emission, viz. ${ }^{5} \mathrm{E}(\mathrm{D}) \leftarrow{ }^{5} \mathrm{~T}_{2}(\mathrm{D})$ of $\mathrm{V}^{+}$.

\section{Computation of the Crystal Field Levels of $\mathrm{V}^{2+}\left(\mathrm{d}^{3}\right)$ and $\mathrm{V}^{3+}\left(\mathrm{d}^{2}\right)$ Ions}

The classical approach of calculating the eigenvalues for excited states of substitutional $3 \mathrm{~d}$ impurities is the method of Tanabe and Sugano [36], which is based on the strong-field scheme, with neglect of spin-orbit coupling. While spin-orbit and Jahn-Teller effects are still considered to be of minor importance for the purpose intended here, two distinct amendments are included in the present approximation:

(i) The treatment is extended to describe also the free-ion terms of the respective configuration.

(ii) By a modification of the conventional crystal-field theory, it is possible to consider a dependence of the radial components of the d electron wave functions on the angular symmetry ( $\mathrm{t}_{2}$ or e) [37]. 
The proposed scheme has successfully been applied to $\mathrm{Mn}^{2+}\left(\mathrm{d}^{5}\right)$ ions [38] and, in the course of the present deliberations, to $\mathrm{V}^{3+}\left(\mathrm{d}^{2}\right)[39]$ and $\mathrm{V}^{2+}\left(\mathrm{d}^{3}\right)[9]$ as well. For details, the reader is referred to these papers. Here, only the main lines of reasoning are presented, and such results as can be compared with the measurements.

The spectra of the free $\mathrm{V}^{3+}\left(\mathrm{d}^{2}\right)$ ion can be fitted by means of the Racah parameters $B=912 \mathrm{~cm}^{-1}$ and $C=3216 \mathrm{~cm}^{-1}$. They describe electron repulsion and manifest themselves in the relative positions of the free-ion terms. In addition, a configurational-correction coefficient $\alpha=75 \mathrm{~cm}^{-1}$ was introduced [40,41], expressing the disparate influence of those configurations whose electron number is different by two from the one considered. The values of $C / B=3.53$ and $\alpha$ are then retained for the same ion incorporated in the tetrahedral crystal environment, and application of the Tanabe-Sugano scheme renders the crystal-field parameter $D q=586 \mathrm{~cm}^{-1}$ and $B=470 \mathrm{~cm}^{-1}$. Besides ${ }^{3} \mathrm{~T}_{2}(\mathrm{~F})=5859 \mathrm{~cm}^{-1}$, the resulting levels are indicated in Figure 4. A satisfactory agreement with the experimental data is obtained. Evidently, spin-flip transitions to the singlet levels hardly contribute to the observed excitation bands.

In the outlined fit, no covalency effects of the type (ii) characterised above are included. With a small contribution of this influence $(X=0.988$, see below for explanation), a different set of parameters ( $D q=244 \mathrm{~cm}^{-1}, B=470 \mathrm{~cm}^{-1}$ ) results, which yields a fit of comparable accuracy. Since no distinctive criteria are available at present, the plain model given initially is still favoured. The strongest band in the spectrum (cf. Fig. 4) is assigned to the ${ }^{3} \mathrm{~T}_{1}(\mathrm{P})$ level, while ${ }^{3} \mathrm{~T}_{1}(\mathrm{~F})$ emerges with higher energy here. The splitting of about $600 \mathrm{~cm}^{-1}$ in the ${ }^{3} \mathrm{~T}_{1}(\mathrm{P}) \leftarrow{ }^{3} \mathrm{~A}_{2}(\mathrm{~F})$ main transition indicates a Jahn-Teller splitting of the excited state which is also apparent in the $\mathrm{GaAs}: \mathrm{V}^{3+}$ excitation spectrum (cf. [23]) and has earlier been related to this effect [20].

Several procedures have been tried to fit the freeion data for $\mathrm{V}^{2+}\left(\mathrm{d}^{3}\right)$ [42]. The best approximation is obtained for $B=787 \mathrm{~cm}^{-1}, C=2740 \mathrm{~cm}^{-1}$ and $\alpha=48 \mathrm{~cm}^{-1}$. Again, the ratio $C / B$ and $\alpha$ are kept constant for the crystal-field case. Possible implications of this presumption, which is made for simplicity, are discussed in previous papers $[9,39]$. In addition to the splitting parameter $D q$ of the static crystal field theory, two parameters $X$ and $Y$ are here introduced [37] which characterise the extension of the radial part of the d electron's wave function. While for the free ion this extension is determined by an effective charge $Z$, the corresponding quantities are $Y Z$ for e-type and $X Y Z$ for $\mathrm{t}_{2}$-type wave functions in the crystal. The given products indicate the different degree of screening (of the core potential) that is exerted by the ligands on these e or $\mathrm{t}_{2}$-type orbitals, respectively. Note that $X$ measures the ratio between these quantities. While $X=1$ for the case of free ions, $X<1$ implies that $\mathrm{t}_{2}$ has a larger range than the erbital.

In the conventional model of Tanabe and Sugano [36], $X=1$ still holds. For a constant $C / B$ ratio, a variation of $Y$ corresponds to changing $B$. If the ${ }^{4} \mathrm{~T}_{2}(\mathrm{~F})$ level position is fixed by the assignment of the emission NPL, the excitation spectrum (cf. Fig. 5) can be fitted with $B=320 \mathrm{~cm}^{-1}$ (or $Y=0.59$ ) and $D q=555 \mathrm{~cm}^{-1}$. Evidently, the number of calculated levels is greater than that of experimental peaks. The ${ }^{4} \mathrm{~T}_{2}(\mathrm{P})$ term is subject not only to spin-orbit splitting but also to Jahn-Teller interaction which accounts for the $9400-8600 \mathrm{~cm}^{-1}=800 \mathrm{~cm}^{-1}$ main splitting of the respective band. The band around $10800 \mathrm{~cm}^{-1}$ contains not only ${ }^{4} \mathrm{~A}_{2}(\mathrm{~F})$ states but in addition various doublets, as depicted in Figure 5. These contribute obviously to the measured strength of this band which otherwise would be expected to be much smaller, since on the grounds of strong-field configuration reasoning, the $t_{2}^{3}$ configuration of ${ }^{4} A_{2}(F)$ could, from the $t_{2} e^{2}$ ground state, only be attained in a two-electron transition, which is, of course, strongly forbidden. The notable role played by doublet states in the excitation of the quartet ${ }^{4} \mathrm{~T}_{2}(\mathrm{~F}) \rightarrow{ }^{4} \mathrm{~T}_{1}(\mathrm{~F})$ emission of $\mathrm{V}^{2+}\left(\mathrm{d}^{3}\right)$ becomes further evident by the considerable strength of the doublet transitions in the $12000-17000 \mathrm{~cm}^{-1}$ range. A potentiality of spin-flip transitions to excite transition-metal luminescence has earlier been demonstrated with $\mathrm{ZnS}: \mathrm{Ni}$ [43].

The extended Tanabe-Sugano model $(X \neq 1)$ is fairly expensive in time and effort, therefore, the computation was restricted to ${ }^{2} \mathrm{~T}_{1}$ and ${ }^{2} \mathrm{E}$ levels, whereas ${ }^{2} \mathrm{~T}_{2}$, ${ }^{2} A_{1}$, and ${ }^{2} A_{2}$ were omitted. The resulting fit is similar to the $X=1$ case, on using the following parameters: $X=0.988, Y=0.58$, and $D q=424 \mathrm{~cm}^{-1}$. The $Y$ value given implies $B=322 \mathrm{~cm}^{-1}$ for $\mathrm{e}^{2}$-type configurations; if also $t_{2}$ orbitals are occupied, $B$ diminishes by a few per cent. The remarkable reduction of $D q$ versus the $X=1$ approximation is due to the direct consideration of altered Coulomb forces for $\mathrm{t}_{2}$ and e orbitals in the amended model so that the interpretation of the observed level separations is here changed. While both 
models produce nearly equal screening, as evidenced by the $B$ values, the covalency effect as considered in the $X \neq 1$ model brings about a splitting of the $\mathrm{t}_{2}$ - and e-type one-electron states even for $D q=0$, thus expressing different overlap of these d electron orbitals with those of the ligands.

\section{Conclusions}

In the low-temperature luminescence spectrum of $\mathrm{ZnS}: \mathrm{V}$ synthetic crystals, three regions of structured emission bands are discernible which are assigned to crystal-field internal transitions of substitutional $\mathrm{V}^{3+}\left(\mathrm{d}^{2}\right), \mathrm{V}^{2+}\left(\mathrm{d}^{3}\right)$ and, with somewhat less conclusive arguments, $\mathrm{V}^{+}\left(\mathrm{d}^{4}\right)$, see Figure 1. By thermalisation studies of the $\mathrm{V}^{3+}$ and $\mathrm{V}^{2+}$ no-phonon lines in these spectra (Figs. 2 and 3), evidence has been obtained for the fine-structure of the initial states which are subject to spin-orbit and dynamic Jahn-Teller splittings. Excitation spectroscopy for the individual $\mathrm{V}^{3+}$ and $\mathrm{V}^{2+}$ photoluminescence bands (Figs. 4 and 5) contributes further to an identification of the respective vanadium oxidation states involved and to an understanding of their excited states as far as they lie in the forbidden gap of the $\mathrm{ZnS}$ band structure. The absorption spec-

[1] M. Avinor and G. Meijer, J. Phys. Chem. Solids 12, 211 (1960).

[2] G. Meijer and M. Avinor, Excitation spectra of vanadium-activated zinc and cadmium sulphide and selenide phosphors. Philips Res. Repts. 15, 225 (1960).

[3] J. W. Allen, Physica 29, 764 (1963).

[4] W. C. Holton, J. Schneider, and T. L. Estle, Phys. Rev. 133, A1638 (1964).

[5] Le Manh Hoang and J. M. Baranowski, Phys. Stat. Sol. B 84, 361 (1977).

[6] J. Schneider, B. Dischler, and A. Räuber, Solid State Commun. 5, 603 (1967).

[7] D. Buhmann, H.-J. Schulz, and M. Thiede, Phys. Rev. B 19, 5360 (1979).

[8] G. Roussos and H.-J. Schulz, Identification of different charge states of vanadium ions in $\mathrm{ZnS}$ crystals by optical spectroscopy. Europhysics Conf. Abstr. 9A; 5th Gen. Conf. Cond. Matter Div., EPS, Berlin 1985, PWe-8-152.

[9] S. W. Biernacki, G. Roussos, and H.-J. Schulz, J. Phys. C: Solid State Phys. 21, 5615 (1988).

[10] U. Kaufmann, H. Ennen, J. Schneider, R. Wörner, J. Weber, and F. Köhl, Phys. Rev. B 25, 5598 (1982).

[11] M. S. Skolnick, P. J. Dean, M. J. Kane, C. Uihlein, D. J. Robbins, W. Hayes, B. Cockayne, and W. R. MacEwan, J. Phys. C: Solid State Phys. 16, L767 (1983).

[12] G. Armelles, J. Barrau, and D. Thébault, J. Phys. C: Solid State Phys. 17, 6883 (1984).

[13] G. Armelles, J. Barrau, D. Thébault, and M. Brousseau, J. Physique 45, 1795 (1984). trum (Fig. 6) is in agreement with the conclusions drawn from the other experimental data.

A model of one-electron states is proposed to reconcile the experimental results, especially those referring to changes in the vanadium charge states (Figure 7). The internal transitions of $\mathrm{V}^{3+}$ and $\mathrm{V}^{2+}$, as mainly displayed in the excitation spectra, are treated in a Tanabe-Sugano-type computational approach. Starting from a successful attempt to fit the reported freeion data, the $\mathrm{V}^{3+}$ crystal-field spectra can be fairly well approximated without referring to covalent contributions. For $\mathrm{V}^{2+}$, even the free-ion energies can only be represented with about $400 \mathrm{~cm}^{-1}$ maximum deviation. Considering this limitation for the expected crystal-field fit, the results are satisfactory as well, this time upon inclusion of a small degree of covalent binding. Although a quantitative comparison with other contemporary theoretical approaches $[44,45]$ is difficult due to incompatibility of the characteristic physical parameters used in these descriptions, an overall agreement with known trends in the positions of impurity energy levels is obvious [46, 47].

\section{Acknowledgements}

Thanks are due Ing. grad M. Thiede for technical assistance with the measurements.

[14] K. J. Nash, M. S. Skolnick, B. Cockayne, and W. R. MacEwan, J. Phys. C: Solid State Phys. 17, 6199 (1984).

[15] G. Aszódi and U. Kaufmann, Phys. Rev. B 32, 7108 (1985).

[16] B. Lambert, H.-J. von Bardeleben, and B. Deveaud, J. Phys. C: Solid State Phys. 18, L707 (1985).

[17] F. G. Anderson and F. S. Ham, Detecting the dynamic aspect of the Jahn-Teller coupling for the $\mathrm{V}^{3+}$ defect in GaAs. 15th Intl. Conf. on Defects in Semiconductors, Budapest 1988, Abstr. p. 38.

[18] K. Kunc, Ann. Phys. Paris 8, 319 (1973/74).

[18 a] G. Roussos, J. Nagel, and H.-J. Schulz, Z. Phys. B 53, 95 (1983).

[19] G. Grebe and H.-J. Schulz, Z. Naturforsch. 29a, 1803 (1974); Erratum 30a, 570 (1975).

[20] A. Mircea-Roussel, G. M. Martin, and J. E. Lowther, Solid State Commun. 36, 171 (1980).

[21] B. Clerjaud, C. Naud, B. Deveaud, B. Lambert, B. Plot, G. Bremond, C. Benjeddou, G. Guillot, and A. Nouailhat, J. Appl. Phys. 58, 4207 (1985).

[22] F. Litty, P. Leyral, S. Loualiche, A. Nouailhat, G. Guillot, and M. Lannoo, Physica B 117/118, 182 (1983).

[23] H.-J, Schulz and M. Thiede, J. Phys. C: Solid State Phys. 21, L1033 (1988).

[24] A. M. Hennel, C. D. Brandt, K. Y. Ko, J. Lagowski, and H. C. Gatos, J. Appl. Phys. 62, 163 (1987).

[25] H. Katayama-Yoshida and A. Zunger, Phys. Rev. B 33, 2961 (1986).

[26] M. J. Caldas, S. K. Figueiredo, and A. Fazzio, Phys. Rev. B 33, 7102 (1986). 
[27] H. A. Weakliem, J. Chem. Phys. 36, 2117 (1962).

[28] U. G. Kaufmann and P. Koidl, J. Phys. C: Solid State Phys. 7, 791 (1974)

[29] G. Roussos and H.-J. Schulz, Phys. Stat. Sol. B 100, 577 (1980).

[30] J. W. Allen, Energy levels of transition metal impurities in semiconductors. 7th Intl. Conf. on Physics in Semiconductors, Paris 1964, Dunod 1964, pp. 781-787.

[31] V. F. Masterov, Fiz. Tekh. Poluprovodn. 18, 3 (1984); Sov. Phys. Semicond. 18, 1 (1984).

[32] H.-J. Schulz, Mater. Chem. Phys. 16, 373 (1987).

[33] B. N. Figgis, Introduction to ligand fields. Interscience Publ. New York 1966.

[34] H.-J. Schulz, J. Cryst. Growth 59, 65 (1982).

[35] P. Schreiber and A. Hausmann, Z. Physik 251, 71 (1972).

[36] Y. Tanabe and S. Sugano, J. Phys. Soc. Japan 9, 753 and 766 (1954).
[37] S. W. Biernacki and H.-J. Schulz, Phys. Stat. Sol. B 103, K163 (1981).

[38] S. W. Biernacki, Phys. Stat. Sol. B 132, 557 (1985).

[39] S. W. Biernacki, G. Roussos, and H.-J. Schulz, Acta Phys. Polon. A 73, 259 (1988).

[40] G. Racah, Phys. Rev. 85, 381 (1952).

[41] R. E. Trees, Phys. Rev. 85, 382 (1952).

[42] Y. Shadmi, E. Caspi, and J. Oreg, J. Res. Nat. Bur. Stand. A73, 173 (1969).

[43] B. Müller, G. Roussos, and H.-J. Schulz, J. Crystal Growth 72, 360 (1985) and Erratum 73, 646 (1985).

[44] A. Fazzio, M. J. Caldas, and A. Zunger, Phys. Rev. B 30, 3430 (1984).

[45] S. Watanabe and H. Kamimura, J. Phys. C: Solid State Phys. 20, 4145 (1987).

[46] H. Hasegawa, Solid State Commun. 58, 157 (1986).

[47] A. Zunger, Solid State Physics, Academic Press, New York 39, 275 (1986). 